\title{
La imposibilidad de una esencia fotográfica como dispositivo técnico. Comentarios a la Estética de la fotografía de Francois Soulages
}

\author{
The impossibility of a photographic essence, as \\ technical device. Notes on the aesthetics of \\ photography by Francois Soulages
}

\author{
José Pablo Concha Lagos \\ Pontificia Universidad Católica de Chile, Chile \\ jconchal@uc.cl
}

- Resumen - En este artículo se problematiza el aporte a la teoría estética de la fotografía del filósofo francés Francois Soulages, desarrollado en su libro Estética de la fotografía. Nos concentraremos en conceptos claves como la fotograficidad, lo irreversible y lo inacabable, presentes en su texto y pensados desde la fotografía análoga. Estos conceptos serán tensionados a partir del rendimiento posible en la fotografía numérico-binaria; así, la esencia de la fotografía se debilita como aquello que la define trascendentalmente, reconociéndose su particularidad según el modo y contexto de uso.

Palabras clave: fotograficidad, irreversible, inacabable, remisionalidad, fotografía.

Abstract - This article discusses the contribution of French philosopher Francois Soulages' «Esthétique de la photographie» to aesthetic theory. We will concentrate on key concepts in his text such as photographicity, irreversible and endless, which are derivative from analogic photography. These concepts will be thought within the possible performance of binary-numeric photography; therefore, the essence of photography weakens in what transcendentally defines it, recognizing its peculiarity by the manner and context of use.

Keywords: photographicity, irreversible, endless, remission, photography. 
Una característica señalada de la fotografía es su remisionalidad, lo que plantea una dificultad en el modo en que es leída. Esto exige definir nítidamente la recepción. Según como sea esta, la foto será comprendida de diversas maneras: como pura semejanza, como icónico-indicial, o desde la condición ideológica de su estructura. Estos tres niveles representan, en términos generales, el consumo popular, la lectura semiológica y, finalmente, la filosófica. Cada una de estas posibilidades define a la fotografía, es decir, no podemos delimitar qué es la fotografía. Esta posición reconoce el lugar en donde la foto opera, lo que le da su horizonte de comprensión, sin que sea posible una definición transversal a todos los usos. Por lo tanto, un acercamiento de carácter metafísico es problemático. Soulages lo plantea de manera explícita al momento de identificar las cuatro rupturas y las cuatro metamorfosis (105). El autor observa que no es posible un encuentro de sentido entre «la cosa en sí» y «la foto recibida». Justamente, un planteamiento de esta naturaleza nos ubica en un ámbito metafísico, en donde la cosa en sí es su fundamento. ¿Pero cómo pensar la cosa en sí de la fotografía si ella es pura remisionalidad? Esta condición de la fotografía dificulta el acceso a ser pensada ontológicamente. Podríamos decir que no hay cosa en sí de la fotografía y sí pura foto recibida. En este sentido, no es viable pensar ningún encuentro, ya que uno de los elementos, para dicho acontecimiento, no puede existir, por lo que un acercamiento metafísico es impracticable.

La remisionalidad no es una característica de la fotografía solamente. En general, todo signo es de esta naturaleza, y no solo los signos: toda herramienta es un objeto remisional, como todo aquello que se constituya en un medio para un fin. Esta característica plantea un asunto clave en la indagación de la cosa en sí, por un lado, y de la esencia, por otro: el objeto remisional reconoce su sentido en algo que no es él. Lo propio de este se encuentra en otro lugar y en otra cosa. El objeto remisional, entonces, es un mero tránsito hacia otro espacio y es ahí donde encuentra su peculiaridad. Pero ¿cómo entender esta función esencial desde Kant, por ejemplo? Como el mismo Soulages señala, Kant establece diferencias fundamentales entre la cosa en sí, el noúmeno y el objeto trascendental, pero lo realmente significativo es que Kant es explícito en afirmar que el individuo solo se las tiene que ver con el fenómeno y es aquí que se reconoce el sentido de la remisionalidad. Kant afirma: «Aunque los fenómenos no sean cosas en sí mismas, son lo único que nos puede ser dado a conocer» (222). La cosa en sí es ubicada en una marginalidad inoperante, es como si no se tomara el riesgo de decir no hay tal cosa en sí, ni noúmeno. La calidad de objeto trascendental, por su parte, no tiene que ver con el objeto, sino que con la síntesis que se tiene al interior de la conciencia de la relación establecida entre la intuición y el fenómeno.

La cosa en sí no es posible de ser reconocida debido a que no hay tal. Si definimos a un determinado ente por sus cualidades, sean estas materiales, funcionales o simbólicas, estas características estarán, eventualmente, presentes en otros entes, y, por lo tanto, no podemos encontrar una «particularidad esencial» de los fenómenos. 
Por ejemplo, en la historia de la fotografía, la definición de carácter material del dispositivo no nos permite llegar a la cosa en sí, porque no siempre ha sido el mismo proceso el que da forma a una imagen fotográfica. La presencia del negativo no puede ser considerada como un aspecto definitorio, ya que, como señala Soulages, tanto en el origen de esta imagen técnica no lo hubo, como no lo hay tampoco en la actualidad; el «objeto» negativo es solo un elemento más que puede estar, como puede no estar, presente, y de igual modo seguirá habiendo fotografía. De la misma manera ocurre con el color y el blanco y negro y la presencia o no de las sales de plata. De hecho, no es necesaria la cámara fotográfica, ni las sales de plata, para obtener imágenes que se inscriban en «lo fotográfico», como es el caso de la obra del fotógrafo Pepe Guzmán, quien ha realizado una serie de retratos con una fotocopiadora. La determinación de lo propio de la fotografía queda desplazada a su función, la que, a su vez, es definida por la manera en que es recibida y comprendida.

Soulages es arriesgado en ofrecer una definición de lo propio de la fotografía a partir del concepto de fotograficidad, o el riesgo es que la propuesta no sea lo suficientemente abarcadora para todo fenómeno fotográfico. Esta definición se sostiene en la materialidad fotográfica, la que se articula en la toma, en el disparo de la cámara, la obtención del negativo y su positivación. Todo el proceso es resumido por Soulages en que «[...] la fotograficidad es esa articulación sorprendente de lo irreversible y lo inacabable» (135). En ambos casos -lo irreversible y lo inacabable- aquello que los sostiene es «el negativo» fotográfico.

Esta definición expone dos problemas: el primero es de orden temporal-tecnológico. Si bien la fotografía, construida a partir de sales de plata (en términos generales) aún se produce, cada vez está más desplazada a márgenes que se circunscriben a grupos especializados, lo que se opone a la tradición popular de la producción y consumo de la imagen fotográfica. Es pertinente advertir al respecto la urgencia de pensar la sustitución de la fotografía análoga por la numérico-binaria (volveremos sobre esto). El segundo problema está referido a la delimitación de lo fotográfico al mero negativo, lo cual restringe posibilidades exploradas por los fotógrafos en lo que Flusser llamó el programa fotográfico. Esta restricción se advierte como cierto conservadurismo en la línea de que lo fotográfico se daría, por ejemplo, en el uso del negativo completo, al modo de Cartier-Bresson. La asimilación de lo propuesto por Soulages a lo planteado por el fotógrafo, podría pensarse, obliga a advertir sus distintos niveles o campos de reflexión; el primero, en un nivel material del dispositivo; el segundo, en un nivel puramente estético. Sin embargo, parece haber un equívoco de base desde el momento en que el mismo negativo puede ser manipulado posteriormente a la toma. Plantearlo como algo definitivo sitúa a la materia fotográfica en dimensiones temporales y espaciales absolutas y autónomas del fotógrafo. La intervención del negativo ha sido una práctica fotográfica largamente desarrollada, uno de sus exponentes es el propio Robert Frank. La definición a partir de los conceptos propuestos por Soulages ubica al fotógrafo en la calidad de mero operador del dispositivo (cfr. Flusser), pero lo 
interesante es que la modificación del negativo, luego de su exposición, solo es posible desde el dispositivo fotográfico y, en este sentido, aparece lo inacabable del negativo como propiedad fotográfica única. Lo que se problematiza con esta definición de lo fotográfico es que la fotografía solo construiría un contenido simbólico desde la pura materialidad fotográfica, del registro de un determinado referente, restringiendo las posibilidades expresivas en intervenciones de esa materialidad. Pero lo irreversible no es el negativo, sino el «acto fotográfico». Pero ¿cuál es el verdadero alcance del «acto fotográfico»? ¿Es realmente importante este acto, desde el momento en que frente a una fotografía descontextualizada no soy capaz de reconocer niveles más profundos de significación que la mera literalidad superficial? ¿Otorgarle tal relevancia al acto fotográfico no es sostener, acaso, el valor de lo fotográfico por la indicialidad, la que se constituye en tránsito a un determinado saber que se presume transparente? Es como si el valor de la novela se sostuviera en que el escritor se «sienta» a escribir, como si esto formara parte de la novelicidad de la novela. Es cierto y, además, necesario que exista el «acto fotográfico» para que exista la fotografía, pero, en mi opinión, este acto es el acto común a cualquier ejercicio de creación de cualquier disciplina. El «acto fotográfico» es el acto creativo del fotógrafo, fundado en el propio fotógrafo, cuyo resultado tiene la forma de negativo, pero lo «inacabable» es también propio del negativo y esto es posible porque nunca tendremos acceso a la experiencia fundante del acto fotográfico. El negativo ha sido comprendido como materia metonímica de un acto irreproducible en la temporalidad diacrónica. Ese fragmento fotográfico visto como totalidad implica la imposibilidad de reconocer en el negativo la variedad de tiempos y espacios que operan en el acto: el fotógrafo intenciona su acto desde su condición de autor y la fotografía se determina por las circunstancias específicas de la situación fotográfica; ambos elementos no pueden aparecer de modo explícito en la imagen, no podemos tener acceso a ellos, quedan suspendidos en el pasado, por lo tanto, el referente y su determinación indicial quedan congelados en una ambigüedad existencial.

II

Soulages se plantea el problema de la imagen de matriz numérico-binaria de manera más bien introductoria, de acuerdo a un parámetro en el que la obtención de una imagen de este tipo se realizaba por medio de la digitalización de un negativo o positivo análogo. Esta práctica definiría una estética de la «hibridación». Naturalmente, en el momento en que se escribió este libro, la masificación de la fotografía digital no era lo que es hoy. El mercado fotográfico se concentra por estos días casi únicamente en la fotografía digital.

La estética de la hibridación se definía, entonces, por la combinación de dos modos de producción de imagen; hoy uno de ellos no es necesario, por lo tanto, solo nos queda por pensar una «estética digital». 
Pero, antes de una «estética de la fotografía digital», es relevante observar algunos aspectos significativos de «lo digital». Una característica clave de este sistema de almacenamiento y manipulación de información es que es inmaterial. Esto ya se plantea como fundamentalmente distinto respecto de la fotografía análoga. La digital es el resultado de cierta manera de usar el código numérico-binario que, en este caso, tiene por objetivo conseguir una imagen fija. Esta estructura material define la calidad óntica para su aparición como superficie impresa; luego del proceso de «lectura» de cierta estructura lingüística numérico-binaria, surge la superficie imaginaria fotográfica. Basta una secuencia numérico-binaria para que aparezca una imagen «fotográfica». Dicho semiológicamente, la fotografía digital elimina todo componente indicial, dejando únicamente los de carácter icónico y simbólico.

El sistema de producción de esta imagen, como componente estructural de una estética de la fotografía digital, se diferencia del sistema análogo, fundamentalmente, en que se pierde definitivamente el «acto fotográfico». Esta pérdida es significativa, ya que la lectura de cualquier imagen de esta naturaleza deberá considerar que, aquello que aparece como fotografía, potencialmente nunca existió. Esta nueva circunstancia obliga a pensar la pérdida de la experiencia como elemento sustancial. La única manera de encontrar al referente en la imagen es a partir de la confianza que se deposite en el fotógrafo, es decir, si aceptamos el relato contextualizador del autor. La ausencia de indicialidad nos obliga a este acto de confianza; la otra posible opción es simplemente no considerar para el análisis estético la pérdida indicial. Si bien la fotografía análoga es una imagen altamente codificada, siempre mantuvo un residuo indicial, en cambio, la fotografía digital lo elimina del todo, abriéndose a una interpretación puramente simbólico-alegórica. Esta calidad interpretativa abre un espacio de libertad en la interpretación fotográfica, aun cuando el uso masivo de la fotografía numérico-binaria todavía la considere como vehiculadora de contenidos objetivizantes. La asignación de un sentido icónico-simbólico a la fotografía actual se debe comprender desde una intensificación de sus características codificadas a partir de dos dimensiones: primero, la perspectiva y segundo, el lenguaje binario. La luz, al entrar por la estenope, se ordena en función de un punto de vista único que toma como eje al punto de fuga. La tridimensionalidad se ajusta al plano bidimensional constreñida a partir de las líneas de fuga. Esta transformación de la luz tiene una dimensión ontológica en la medida en que se desnaturaliza al modificarse fenomenológicamente. Inmediatamente después, esta luz alterada nuevamente se codifica, pero en código binario. La naturaleza hermética de este lenguaje impide la decodificación, obligando al uso de un sistema decodificador específico, el software.

Esta doble codificación aleja inexorablemente, desde una perspectiva ideológica -en tanto configuración de mundo presente en un sistema imaginario coherente de representación-, al objeto de su representación fotográfica. De tal modo, esta pérdida abre las posibilidades alegóricas de la fotografía numérico-binaria. 
La estética de la hibridación, que propone Soulages, es superada por una estética de lo digital que pone énfasis en la alegoría, como categoría, a partir de la independencia de la imagen de los procesos y materias fotografiadas. Esta radicalidad disciplinar se funda en la abstracción lingüística de la fotografía numérico-binaria. La «fotograficidad», como fundamento de una estética de la fotografía, es abolida por la «inmaterialidad». Esta, en tanto fundamento de esta estética, implica una autonomía del significado de la superficie fotográfica, lo que se constituye en una modificación sustancial de «lo fotográfico». Se pasa de la fotografía como «ente» a la fotografía como «concepto». Esta idea ya fue adelantada por Vilem Flusser en su texto fundamental Hacia una filosofía de la fotografía, la diferencia, desde la perspectiva actual, es que la condición de concepto no se da desde una pura perspectiva cultural, como lo plantea Flusser, sino que desde la propia constitución estructural de la imagen fotográfica. La abstracción que implica la conceptualización de la fotografía numérico-binaria no es desde la pérdida de algunas dimensiones de la realidad que quedan contenidas en las que permanecen, sino que se abstraen de la «abstracción» que significa la convención perspéctica de la figuración bidimensional. De este modo, lo «inacabable» como principio fotográfico se radicaliza desde el acto fotográfico y desde el archivo. Lo irreversible se comprende solo desde el negativo por lo que, podríamos afirmar aquí, lo propio de la fotografía numérico-binaria es su absoluta «reversibilidad».

\section{III}

La «reversibilidad» impone una reflexión de orden ético sobre la práctica fotográfica y las posibilidades de lectura. Es el «acto fotográfico» el que se desvanece como elemento constituyente de la particularidad fotográfica, pero, además, este acto era el sello de garantía de la materialidad de la fotografía de lo fotografiado. La «irreversibilidad» define la autoridad fotográfica en el contenido de «verdad» irrepetible del acto que la produce. En este acto se concentran: el operador del dispositivo fotográfico, su intencionalidad estética (en cuanto a las decisiones técnico-formales de construcción de la imagen), las capacidades técnicas del aparato fotográfico y lo fotografiado. Esta enumeración expone como variables imprecisas los elementos generales que se articulan al momento de obturar la cámara fotográfica; la imprecisión está comprendida en la imposibilidad de ajustar a proyecciones causales las acciones ejecutadas. Las variables temporales, espaciales, emotivas y técnicas debilitan la consistencia referencial de la imagen. Este hecho es crítico para las intenciones de concebir a la fotografía como portadora de «verdad». Si esta verdad ya no opera, porque la irreversibilidad se sostiene sobre la supuesta inalterabilidad de un acto en el pasado, pero que se desvanece en la imposibilidad de actualizarlo, en la imposibilidad de acceder a él, la autoridad fotográfica desaparece.

No hay contenido de «verdad» en la fotografía digital porque la «irreversibilidad» es una categoría inoperante debido a que el acto irreversible es incomprobable, no 
hay posibilidad de recomponer la huella material de la existencia de aquello que es fotografiado. Por lo tanto, es posible afirmar que el problema ético consiste en que la confianza sobre el contenido fotográfico, todavía hoy, se sostiene en algo que potencialmente nunca existió. Como decíamos en el punto anterior, en la fotografía digital se elimina todo vestigio indicial. De este modo, si el contenido de verdad ya no es posible encontrarlo en la foto misma, ¿entonces dónde? La respuesta es compleja porque la «verdad» estaría contenida en el discurso, relato o testimonio de quien proporciona la imagen. En otras palabras, la verdad está en quien distribuye dicha imagen. Desde esta perspectiva, el problema ético se desplaza hacia otros de carácter político, es decir, el dominio y uso, según necesidades contingentes, del contenido superficial de una imagen. Es decir, no hay contenido específico al interior de la fotografía sino que uno inexorablemente contextual; esto significa que la fotografía se resignifica cada vez que es reubicada y de este modo se abre la posibilidad interpretativa.

\section{IV}

El planteamiento sobre lo fotográfico de Soulages se proyecta también hacia el siguiente problema: la definición de un objeto artístico y la de uno no artístico. Inevitablemente resuena aquí el círculo hermenéutico heideggeriano que pretende, justamente, resolver el enigma del «arte». En resumen, es arte aquello que hace un artista y es artista quien realiza obras de arte, pero, como dice Heidegger, lo que falta acá es el fundamento de ambos: el arte. Si bien la reflexión heideggeriana no está en consonancia con lo que ocurre en su tiempo con la creación artística (es como si no supiera de la existencia de las vanguardias artísticas europeas) y por esta razón El origen de la obra de arte no cubre los problemas teóricos que plantea la creación en su tiempo, sí es eficiente dentro de su programa filosófico. Pero quisiera detenerme en un aspecto que, creo, ilumina nuestro problema. Metodológicamente, Heidegger desarrolla una fenomenología de la obra de arte (recordemos, eso sí, que las obras que utiliza para su reflexión son de Van Gogh y el arte clásico griego), concentrándose, en un momento, en la condición de cosa de la obra. Luego de esta observación hace un salto a la característica fundamental que él considera en la Aletheia, el desocultar de la obra. Este salto, en algún sentido, nos permite ver dos momentos: el primero nos ubica en un espacio relevante para la reflexión sobre la condición de arte o no arte de una fotografía: la recepción. La calidad de cosa de la obra de arte se reconoce en tanto objeto delante de mi percepción, y por la intencionalidad con que es mirado dicho objeto será arte o no. Poco puede llegar a influir el autor en lo que ocurrirá con su «obra» en la recepción. La distinción entre fotografía con arte y sin arte dependerá del horizonte teórico de la recepción, pero el nivel de proyección de información, sea esta específica o abierta, depende de la intención de recepción. El segundo momento nos sitúa en el ámbito metafísico de la función del arte en tanto verdad. 
No es nuevo plantear que el espacio de exhibición determina el sentido con que es recibida una obra específica; un ejemplo fotográfico claro de esto es lo ocurrido con la obra de Tomás Munita. Su trabajo se circunscribe al género documental y por él ha sido premiado en numerosas oportunidades, por ejemplo, en el año 2006 obtiene un importante reconocimiento en el concurso Leica Oskar Barnack con sus imágenes sobre Kabul, ciudad devastada por la violencia. Luego de este importante premio a fotografías que tenían una motivación fundamentalmente informativa, se organiza en el Museo de Bellas Artes de Chile una gran exposición. Un ejemplo que caracteriza el tránsito desde un espacio de simbolización a otro, o su dificultad, son las fotografías tomadas por soldados norteamericanos a prisioneros en la cárcel de Abu Ghraib. Estas imágenes están imposibilitadas de transitar desde el espacio de simbolización informativa hacia el espacio simbólico del arte. La ausencia de mediación autoral -en términos «creativos»- de un fotógrafo profesional, le otorga a estas imágenes un índice de realidad altamente superior, ya que el observador da por descontado que son fotos reales y filtradas de un hecho que debía mantenerse oculto, es decir, el acceso a esta situación solo era posible para sus protagonistas. La crudeza de estas escenas impide su llegada a espacios museales, pero lo consiguen si son mediadas por un artista, como ocurre con la obra del colombiano Fernando Botero dedicada estos acontecimientos. Estas pinturas reproducen, en el estilo habitual del pintor, las fotografías filtradas, pero mediadas por una estética que las distancia de la calidad de mero documento.

Si seguimos a Soulages, en el caso de Munita opera el tránsito del sin arte al arte sin ninguna dificultad. Pero lo que plantea este hecho es que la misma institucionalidad artística asume como artístico un trabajo que no lo es en su origen. Nos preguntamos finalmente: ¿es relevante hacer la distinción entre arte y no arte? Cada época ha definido lo que comprende como arte, por esta razón no se puede ofrecer una enunciación lo suficientemente abarcadora para considerar como equivalentes manifestaciones que, tanto en sus procesos de producción como en sus sistemas de distribución y en el horizonte teórico de recepción, son totalmente diversas.

\section{V}

La fotografía social anula el juicio estético; por el contrario, una fotografía «estética» dificulta la posibilidad de lectura social. Es decir, la fotografía de carácter social tiene por función básica la de informar, por ejemplo, de un cumpleaños, de una graduación, de una primera comunión en la tradición católica, etc. En estas circunstancias, el observador concentra su atención en los datos reconocibles en la imagen y esto solo es posible por su participación del contexto de producción de la imagen. Si esto no fuera así no podría haber lectura de información. Esto establece una nueva relación entre foto y observador: la mera apreciación fenoménica que toma características estéticas, es decir, la única posibilidad comunicativa se alza alegóricamente desde la superficie fotográfica. Pero esta relación con la fotografía no es la que se encuentra 
en su consumo mediático. Aquí opera, en primer lugar, la relación texto e imagen. El contenido textual determina el contenido fotográfico; siempre será así y esta información entregará a la imagen su posibilidad de sentido y, finalmente, su significado. No hay significado literal si no hay dominio de contexto. Esta afirmación ubica en quien lee la foto la posibilidad de apertura del significado fotográfico. La fotografía descontextualizada es un mero objeto mudo que, aun cuando en su sola materia presenta la capacidad de comunicarse ella misma, no hace posible el ejercicio de acceso a la totalidad del referente como posibilidad de conocimiento. La fotografía en este caso se autonomiza del referente, pero una imagen así, en un diario, es de una incomodidad casi insoportable; el observador requiere de un contexto casi sin darse cuenta. Un ejemplo interesante es lo que ocurre con los libros de fotos documentales: ansiosos buscamos los pie de foto y experimentamos una gran frustración si no están. La segunda relación es entre foto y observador, aquella en que a partir del conocimiento previo del sujeto se le ajustará algún significado. Es decir, a partir de sus referencias visuales previas se construirá un horizonte de sentido, pero este quedará al arbitrio subjetivo de la intencionalidad del lector. La fenomenología ya aclaró, como decíamos más arriba, que toda imagen es intencionada tanto dentro como fuera de la conciencia. En el momento en que la intencionalidad del fotógrafo coincide con el observador se cree estar frente a la lectura de la información.

Estas imágenes transitan libremente desde el espacio informativo al espacio de exhibición, desde el diario o revista a la galería o museo. El fotógrafo, quiéralo o no, se transforma en autor. La «verdad» fotográfica es suspendida por la habilidad estética. Un ejemplo interesante es la muestra que periódicamente se presenta en nuestro país de la fundación World Press Photo. La forman fotografías en su mayoría de un dramatismo casi espeluznante, pero hay que recordar que este es un concurso fotográfico, es decir, se elige a la mejor fotografía y los únicos juicios posibles son de carácter estético. El nivel de identificación con el dolor queda marginado al asombro de la imagen vista, pero la conmiseración se anula como posibilidad de afectación movilizadora.

¿Donde está la tragedia, en tanto objeto registrable, en la fotografía contemporánea? En la fotografía aficionada. La carga de verdad en estas imágenes es de una potencia muchísimo mayor porque en la lectura intencionada se cree que no hay mediación subjetiva ni técnica; en otras palabras, la fotografía de acontecimientos dramáticos sería transparente en tanto contacto directo y no mediado por recursos estéticos ni ideológicos. En este caso, la remisionalidad se hace efectiva porque el dispositivo técnico desaparece de la conciencia tanto del operador como del observador de la fotografía.

Si al principio de este texto afirmábamos que la remisionalidad era un aspecto definitorio de la fotografía, la reflexión nos muestra que esta condición entra en crisis al momento de dirigir la remisionalidad a la presencia del referente. Si no es posible el acceso al objeto fotografiado, lo que nos queda es que la fotografía es una ficción 
simbólica, por lo tanto, la remisionalidad se conduce hacia las posibilidades interpretativas del observador. La fotografía se libera del peso de la revelación ajustada a una experiencia objetivadora.

\section{REFERENCIAS}

Flusser, Vilem. Hacia una filosofía de la fotografía. México: Trillas, 1990. Medio impreso. Heidegger, Martin. «El origen de la obra de arte». Caminos del bosque. Madrid: Alianza Editorial, 1998. Medio impreso.

Kant, Emmanuel. Crítica de la razón pura. Madrid: Alfaguara, 2004. Medio impreso. Soulages, Francois. Estética de la fotografía. Buenos Aires: La Marca, 2005. Medio impreso. 